\title{
A Agenda de Pesquisas da Diest sobre o Poder Legislativo ${ }^{1,2}$
}

Acir Almeida ${ }^{3}$

\section{INTRODUÇÃO}

A agenda de pesquisas da Diretoria de Estudos e Políticas do Estado, das Instituiçóes e da Democracia (Diest) sobre o Poder Legislativo integra a missão mais ampla da diretoria de produzir conhecimento a respeito dos efeitos de instituiçôes políticas sobre o desenvolvimento. Em relação ao tema específico, o objetivo é aprimorar a compreensão acerca do comportamento parlamentar e do funcionamento do Congresso Nacional, de um lado, e dos seus eventuais impactos sobre políticas públicas e a governabilidade, de outro.

Há décadas, essas questôes estáo no centro do debate nacional a respeito do sistema político e suas consequências. Por exemplo, desde o início dos anos 1990, debate-se em que medida nosso desenho institucional, particularmente o federalismo e o multipartidarismo, é pródigo em pontos de veto e, por isso, dificulta a produção e a execução de políticas públicas. Frequentemente, esse debate se materializa em propostas de reforma política, sejam das regras eleitorais, sejam das regras que organizam a produção de leis.

A relevância dessa agenda de pesquisas extrapola a dimensão político-institucional, abarcando as áreas de políticas substantivas às quais o Ipea tradicionalmente se dedica. Conquanto o instituto se notabilize na avaliação da eficácia de políticas, é importante complementar esse aspecto com o da viabilidade legislativa, isto é, a chance de uma política específica ser aprovada no Congresso. Para tanto, é necessário entender o processo decisório, as motivaçóes e o comportamento dos congressistas. Como ficará claro na próxima seção, a relevância desse aspecto tem aumentado progressivamente, em razão da recente descentralização da produção legislativa, com redução do controle do Executivo e ampliaçáo das oportunidades de influência parlamentar.

No restante deste breve artigo, descrevo o contexto da gênese e a evolução da agenda de pesquisas da Diest sobre o Poder Legislativo, aponto suas contribuiçóes e perspectivas futuras e, por fim, reflito sobre o desafio da sua consolidação no Ipea.

\section{GÊNESE E EVOLUÇÃO DA AGENDA DE PESQUISAS}

A agenda de pesquisas da Diest sobre o Poder Legislativo emergiu em face de duas necessidades. A primeira foi entender as causas e consequências de mudanças importantes no funcionamento do Congresso e na sua relação com o Poder Executivo, contemporâneas à criação da diretoria. A outra foi reavaliar a relação entre representação política e governabilidade, isto é, entre os interesses que os congressistas defendem e a capacidade do sistema político de produzir políticas de interesse amplo.

Até o início dos anos 2000, a produção legislativa federal se caracterizava por forte domínio do Poder Executivo, atuação reativa do Congresso e marginalização das suas comissões parlamentares

1. DOI: http://dx.doi.org/10.38116/bapi29art11

2. 0 autor agradece as excelentes sugestões do Comitê Editorial e de Maria Paula Gomes.

3. Técnico de planejamento e pesquisa na Diretoria de Estudos e Políticas do Estado, das Instituições e da Democracia (Diest) do Ipea. 
permanentes. A título de ilustração, das proposições não orçamentárias aprovadas na Câmara dos Deputados (e convertidas em lei), desde 1989 até 2002, 74\% tiveram origem no Executivo, sendo que, desse subconjunto, 71,5\% tramitaram como medida provisória (MP) - logo, sem que comissão permanente pudesse examinar e debater o mérito. ${ }^{4}$ Se, por um lado, esse quadro favorecia a implementação da agenda de políticas do governo - e, de forma mais ampla, a governabilidade -, por outro, ele suscitava preocupaçóes acerca da autonomia e relevância do Congresso. As principais críticas nesse sentido direcionavam-se à MP, uma espécie de poder de decreto do presidente, cujo uso se tornara corriqueiro a despeito de a Constituição Federal reservá-la a situações de relevância e urgência.

A partir de meados dos anos 2000, contudo, notam-se sinais de mudanças no padrão legislativo, na direção de um maior protagonismo do Congresso e das comissões permanentes. De 2003 a 2010, a taxa de dominância do Executivo caiu quase pela metade, e a parcela de leis governamentais aprovadas por meio de MP diminuiu substancialmente. Ambos os fenômenos se observam nas mais diversas áreas de governo, inclusive na econômica. $\mathrm{O}$ crescimento da parcela de leis de origem parlamentar e da participação das comissóes permanentes representa uma descentralização do processo decisório, ampliando as oportunidades de influência de grupos minoritários e as chances de aprovação de políticas não alinhadas com a agenda do governo. Essas mudanças acarretaram uma inversão nos termos do debate político, que passou a girar em torno da possível perda de qualidade das políticas públicas e, mais amplamente, do risco para a governabilidade.

Curiosamente, não se encontrava uma explicação satisfatória para as mudanças, uma vez que nenhum dos principais fatores apontados pela literatura como responsáveis pela (elevada) dominância do Executivo e marginalização das comissões permanentes - quais sejam, as regras eleitorais (Ames, 2003) e a estrutura formal de poderes (Figueiredo e Limongi, 1999; 2007) - havia sofrido alteraçóes relevantes no período. Nossa percepção de que estávamos diante de mudanças potencialmente importantes, porém mal compreendidas, surgiu do primeiro esforço de reflexão da diretoria sobre as instituiçóes políticas do país e o estado da arte, que se materializou no livro Estado, Instituiçôes e Democracia: República (Cunha, Medeiros e Aquino, 2010). No capítulo dedicado ao Congresso, no qual se revisou a literatura empírica sobre seu funcionamento, apontou-se o inédito crescimento da quantidade de leis de origem parlamentar e levantaram-se preocupaçóes com a qualidade do seu conteúdo (Almeida, 2010).

A necessidade de pesquisar as mudanças e, mais amplamente, o funcionamento do Congresso ficou clara diante da preocupação do núcleo do governo, à época, com os modelos de representação parlamentar e de governabilidade. ${ }^{5} \mathrm{Na}$ percepção daqueles atores, a representação era excessivamente fragmentada e particularista, o que tornava muito custosa a produção de políticas, pela morosidade do processo e pelos recursos necessários à manutenção de uma base de apoio majoritária. Por essa ótica, o novo protagonismo do Congresso teria consequências negativas para as políticas públicas e para a governabilidade. Decidimos, então, investir em uma agenda de pesquisas assentada nos eixos da governabilidade e da representação, com os objetivos específicos de investigar a existência de entraves à produção de políticas públicas voltadas para o desenvolvimento, bem como a natureza dos interesses representados no parlamento e sua influência sobre decisóes legislativas. Nosso diagnóstico

4. Incluem-se nesse conjunto as reedições de MPs com alterações substantivas do texto. A inclusão se justifica porque, ausente a possibilidade de reedição, as alterações teriam de ser propostas por nova MP ou projeto de lei.

5. Conforme manifestou a Subchefia de Assuntos Parlamentares (Supar) da Secretaria de Relações Institucionais (SRI) da Presidência da República, em reunião com a Diest, em 2011. 
inicial era de que o conhecimento acumulado a respeito dessas questóes estava em xeque, por não ser capaz de oferecer uma explicação satisfatória para a aparente redução do controle do Executivo sobre a produção legislativa.

De 2011 a 2013, realizamos os primeiros estudos, todos voltados à produção de evidência inédita. Como a diretoria não tinha recursos para avançar simultaneamente nas duas frentes, priorizamos a internalização das pesquisas relativas ao eixo da governabilidade, com foco na investigaçáo da lógica do controle do Executivo sobre a produção legislativa e das causas da sua recente queda.

Deu-se início, então, a um esforço contínuo de coleta e organização de dados originais sobre comportamento parlamentar, produção e processo legislativo, de um lado, e à revisão da literatura teórica, de outro. Analisaram-se a capacidade do Legislativo de obter informação e acumular expertise sobre políticas públicas (Mendes Santos, 2014); a obstrução legislativa e sua relação com o gerenciamento da coalizão de governo (Hiroi e Rennó, 2014); e os condicionantes do uso de MPs (Almeida, 2014a). Nesse processo, privilegiamos discussóes com especialistas da academia e com o corpo técnico do Congresso. Tudo isso resultou, primeiro, em uma descrição e caracterização mais precisa das mudanças legislativas (Almeida, 2014b) e, em seguida, na identificação de um conjunto de hipóteses explicativas, que associam a queda da dominância do Poder Executivo e o novo protagonismo das comissões parlamentares principalmente a dois fatores, sendo um estrutural e outro conjuntural. O primeiro consiste na aparente tendência de queda da representação de interesses locais, desde pelo menos o fim dos anos 1990, sugerida pelo progressivo declínio da concentração municipal dos votos dos deputados (Almeida, 2016). O segundo é a menor polarização ideológica entre a maioria de governo e a minoria opositora, no período de 2003 a 2015 (Almeida, 2016; 2019). Atualmente, essas hipóteses estão na fase final de validação.

No eixo da representação, por sua vez, investigaram-se os efeitos da desproporcionalidade da representação dos estados na execução das emendas parlamentares ao orçamento (Turgeon e Cavalcante, 2014) e a representação de grupos de interesse organizados (Santos, 2014). Esse eixo ganhou novo impulso a partir de 2015, por meio do projeto Dinheiro e Política, no qual se delinearam pesquisas sobre a influência do poder econômico no Legislativo e métodos para avaliar formas de regular o ativismo político de empresas. Com essa iniciativa, procuramos avançar no conhecimento sobre os efeitos do financiamento de campanhas e do lobbying empresarial na Câmara, haja vista a centralidade que essas atividades haviam adquirido no debate político e institucional, em razão de escândalos de corrupção. A execução do projeto, que também se baseou em parceria com pesquisadores externos, gerou dados e evidência inéditos, sobretudo a respeito de doaçóes eleitorais de empresas e lobbying (Araújo e Speck, 2019; Santos et al., 2017), e da relação entre essas atividades e a atuação parlamentar (Mancuso et al., 2019; Santos et al., 2019). Atualmente, estamos compilando e analisando seus resultados para definir os passos seguintes.

\section{CONTRIBUIÇÕES E LACUNAS}

As pesquisas que a Diest realizou geraram contribuições relevantes para o campo dos estudos legislativos e, mais amplamente, para o debate político e institucional. Isso é mais nítido no eixo da governabilidade. $\mathrm{O}$ principal aporte das pesquisas nesse tema consistiu em argumentos teóricos sólidos e evidência empírica conclusiva de que a dominância do Executivo é reflexo de uma delegação do Congresso, que, por seu turno, é condicionada aos interesses de uma maioria parlamentar. 
Esse achado permite, por exemplo, rejeitar a tese de que o uso de MPs e o domínio legislativo do Executivo refletem a ação unilateral do presidente. Até então, o debate delegação versus ação unilateral não havia gerado evidência conclusiva.

O conhecimento produzido pela diretoria a respeito do tema governabilidade também tem ajudado a iluminar o debate público. Isso ocorreu, por exemplo, quando da discussão sobre os impactos da Emenda Constitucional no 32/2001, que restringiu a edição de MPs. A percepção sobre essa reforma era negativa porque, aparentemente, o uso do instrumento havia se intensificado nos anos seguintes. No entanto, um estudo da diretoria mostrou que o único conjunto de MPs convertidas em lei que aumentou após a emenda foi o das suplementações orçamentárias (Almeida, 2011).

Esse estudo se desdobrou em uma análise das críticas de que o uso de MPs em suplementaçóes orçamentárias permitia ao governo burlar a autorizaçáo legislativa e, assim, executar um orçamento paralelo. Nossas análises complementares revelaram, entâo, os mecanismos do efeito (não antecipado) da Emenda no 32/2001 sobre o crescimento do uso de MPs orçamentárias, e mostraram que esse fenômeno refletiu uma abdicação deliberada de controle pelos congressistas, o que, contudo, não desvirtuou o orçamento originalmente aprovado (Almeida, 2018, cap. 6).

A última intervenção no debate público ocorreu em 2020, quando a Diest fez uso do seu conhecimento acumulado para refutar críticas de que o protagonismo do Congresso é oportunista e ilegítimo, ponderando que ele reflete uma tendência estrutural que se iniciou muito antes do atual governo, e que sua recente intensificação é consistente com a presente configuração política, de governo minoritário e polarizado (Almeida, 2020).

Ainda a respeito dos aportes das nossas pesquisas, deve-se destacar que eles têm a desejável propriedade de serem cumulativos, no sentido de que todo o conhecimento novo aqui gerado se constrói a partir do conhecimento já consolidado no campo, permitindo que se reforce progressivamente sua validade e, assim, diminua a incerteza acerca dos efeitos esperados. Por exemplo, para explicar as mudanças legislativas e, mais amplamente, a relação entre o Poder Executivo e o Congresso, combinamos os achados empíricos dos estudos sobre o caso brasileiro com o conhecimento teórico mais geral da literatura sobre organização e delegação legislativa. Conseguimos, assim, oferecer uma interpretação mais precisa e bem fundamentada daquelas mudanças, capaz de se desdobrar em implicaçóes empíricas acerca de diferentes aspectos do processo legislativo (como o uso de MPs), que, por seu turno, constituem-se em oportunidades adicionais de teste da nossa interpretação. À medida que se validem as implicaçôes, aumentar-se-á a confiança em nossa interpretação.

Não obstante o nítido progresso da nossa agenda de pesquisas sobre o Legislativo, persistem lacunas importantes em cujo preenchimento pesquisas futuras deverão focar. Talvez a mais importante de todas sejam as consequências substantivas do novo protagonismo do Congresso. Quais sáo os efeitos esperados sobre o conteúdo das políticas? Para responder a essa pergunta, será necessário avançar no eixo da representação, mais precisamente na identificação do perfil dos interesses que os parlamentares defendem. Outra lacuna importante é o papel e a relevância das comissóes permanentes, sobretudo as da Câmara. Por muitos anos, a centralização das decisões no plenário justificou negligenciar essas arenas. No contexto atual, em que elas participam significativamente da deliberação, é necessário compreender os interesses nelas representados, a natureza da sua atuação e sua influência sobre resultados legislativos. 


\section{CONSIDERAÇÕES FINAIS}

A Diest teve papel pioneiro na identificação, na caracterização e na explicação de importantes mudanças na produçáo legislativa e no funcionamento do Congresso. Nos seus primeiros dez anos de existência, a diretoria investiu na construção de bancos de dados originais, na fundamentação teórica das suas análises, na produção de evidência empírica de qualidade e, acima de tudo, conseguiu acumular conhecimento relevante tanto para o debate acadêmico como para o político-institucional.

Não obstante esse bom desempenho inicial, é importante apontar um desafio à consolidação de uma agenda de pesquisas sobre o Poder Legislativo e instituiçóes políticas no âmbito do Ipea. Como as regras que organizam a competição eleitoral e a relação entre os Poderes impactam diretamente carreiras e prerrogativas parlamentares, quando se trata de reformas políticas o Congresso raramente delega a iniciativa de formulação e geralmente toma decisóes pensando mais nas consequências imediatas para seus membros que nos efeitos mais amplos sobre o sistema político. Por isso, tende a ser baixa a capacidade do Executivo de influenciar reformas políticas, especialmente por meio de recomendaçóes técnicas, ${ }^{6}$ o que, em consequência, reduz seu incentivo para investir na aquisição e acúmulo de expertise nessa área.

A despeito disso, é importante que o Ipea invista em uma agenda de pesquisas sobre o Legislativo, uma vez que a relação entre instituiçóes políticas e desenvolvimento interessa a todos não só ao Congresso, não só ao Estado, mas também à sociedade civil. Nesse sentido, o instituto tem o importante papel de extravasar essa discussão do âmbito do Congresso, disseminando-a pela sociedade.

\section{REFERÊNCIAS}

ALMEIDA, A. O Congresso Nacional no pós-1988: capacidade e atuação na produção de políticas e no controle do executivo. In: CUNHA, M.; MEDEIROS, B.; AQUINO, L. (Org.). Estado, instituiçóes e democracia: República. Brasília: Ipea, 2010. p. 97-130.

. Avaliação do impacto da Emenda 32 sobre a edição de medidas provisórias. Brasília: Ipea, 2011. (Comunicados do Ipea, n. 103).

. Informação, delegação e processo legislativo: a política das medidas provisórias. Brasília: Ipea, 2014a. (Texto para Discussão, n. 1933).

- A produção legislativa no pós-1988: tendências recentes e desafios. In: MONASTERIO, L. M.; NERI, M. C.; SOARES, S. S. D. (Ed.). Brasil em desenvolvimento 2014: estado, planejamento e políticas públicas. Brasília: Ipea, 2014b. p. 247-260.

. A política da mudança institucional: processo legislativo no Brasil pós-1988. In: ENCONTRO ANUAL DA ANPOCS, XL. Caxambu: ANPOCS, 2016. Mimeografado.

6. Um exemplo ilustrativo foi a experiência de formulação do Plano Brasil 2022 pela Secretaria de Assuntos Estratégicos. Após semanas de trabalho, o grupo encarregado de propor reformas institucionais para aprimorar a governabilidade foi desincentivado a continuar mediante a alegação de que seria infrutífero, dado que o Congresso costuma priorizar suas próprias iniciativas. 
Governo presidencial condicionado: delegação e participação legislativa na Câmara dos Deputados. 2018. Tese (Doutorado) - Instituto de Estudos Sociais e Políticos, Universidade do Estado do Rio de Janeiro, Rio de Janeiro, 2018.

. Do plenário às comissóes: mudança institucional na Câmara dos Deputados. In: PERLIN, G.; SANTOS, M. L. (Org.). Presidencialismo de coalizáo em movimento. Brasília: Câmara dos Deputados, Ediçóes Câmara, 2019.

. Relaçóes Executivo-Legislativo e governabilidade à luz da crise da Covid-19. Brasília: Ipea, 2020. (Nota Técnica, n. 34).

AMES, B. Os entraves da democracia no Brasil. Rio de Janeiro: Editora FGV, 2003.

ARAÚJO, V.; SPECK, B. W. Ativismo eleitoral das empresas e dos setores produtivos. Boletim de Análise Político-Institucional. Brasília: Ipea, n. 21, 2019.

CUNHA, M.; MEDEIROS, B.; AQUINO, L. (Org.). Estado, instituiçóes e democracia: República. Brasília: Ipea, 2010.

FIGUEIREDO, A. C.; LIMONGI, F. Executivo e Legislativo na nova ordem constitucional. Rio de Janeiro: Editora FGV, 1999.

- Instituiçóes políticas e governabilidade: desempenho do governo e apoio legislativo na democracia brasileira. In: MELO, C. R.; SÁEZ, M. A. (Org.). A democracia brasileira: balanço e perspectivas para o século 21. Belo Horizonte: Editora UFMG, 2007.

HIROI, T.; RENNÓ, L. Obstrução e processo decisório na Câmara dos Deputados. Brasília: Ipea, 2014. (Texto para Discussáo, n. 1957).

MANCUSO, W. P. et al. Financiamento eleitoral e comportamento parlamentar: a relação entre doaçôes da indústria e proposição de leis. Boletim de Análise Político-Institucional. Brasília: Ipea, n. 21, 2019.

MENDES SANTOS, F. G. O Legislativo em busca de informação: um estudo da estrutura de assessoria da Câmara dos Deputados. Brasília: Ipea, 2014. (Texto para Discussão, n. 1958).

SANTOS, M. L. Representação de interesses na arena legislativa: os grupos de pressão na Câmara dos Deputados (1983-2012). Brasília: Ipea, 2014. (Texto para Discussão, n. 1975).

SANTOS, M. L. et al. Lobbying no Brasil: profissionalização, estratégias e influência. Brasília: Ipea, 2017. (Texto para Discussão, n. 2334).

. Financiamento e lobbying empresarial na comissão de indústria e comércio e de agricultura. Boletim de Análise Político-Institucional. Brasília: Ipea, n. 21, 2019.

TURGEON, M.; CAVALCANTE, P. Desproporcionalidade da representaçáo dos estados no Congresso Nacional e seus efeitos na alocaçáo dos recursos federais. Brasília: Ipea, 2014. (Texto para Discussão, n. 1980). 